San Jose State University

SJSU ScholarWorks

Master's Theses

Master's Theses and Graduate Research

Spring 2012

\title{
The Examination of the Moderating Variables of Job Exposure and Need for Cognition on the Effects of Type of Job Preview on Pre-Hire Outcomes
}

Ashley Jo Hacnik

San Jose State University

Follow this and additional works at: https://scholarworks.sjsu.edu/etd_theses

\section{Recommended Citation}

Hacnik, Ashley Jo, "The Examination of the Moderating Variables of Job Exposure and Need for Cognition on the Effects of Type of Job Preview on Pre-Hire Outcomes" (2012). Master's Theses. 4135.

DOI: https://doi.org/10.31979/etd.gj5t-yhjd

https://scholarworks.sjsu.edu/etd_theses/4135

This Thesis is brought to you for free and open access by the Master's Theses and Graduate Research at SJSU ScholarWorks. It has been accepted for inclusion in Master's Theses by an authorized administrator of SJSU ScholarWorks. For more information, please contact scholarworks@sjsu.edu. 
THE EXAMINATION OF THE MODERATING VARIABLES OF JOB EXPOSURE AND NEED FOR COGNITION ON THE EFFECTS OF TYPE OF JOB PREVIEW ON PRE-HIRE OUTCOMES

\author{
A Thesis \\ Presented to \\ The Faculty of the Department of Psychology \\ San José State University \\ In Partial Fulfillment \\ Of the Requirements for the Degree \\ Master of Science
}

by

Ashley Jo Hacnik

May 2012 
(C) 2012

Ashley Jo Hacnik

ALL RIGHTS RESERVED 
The Designated Thesis Committee Approves the Thesis Titled

THE EXAMINATION OF THE MODERATING VARIABLES OF JOB EXPOSURE AND NEED FOR COGNITION ON THE EFFECTS OF TYPE OF JOB PREVIEW ON PRE-HIRE OUTCOMES

by

Ashley Jo Hacnik

APPROVED FOR THE DEPARTMENT OF PSYCHOLOGY

SAN JOSÉ STATE UNIVERSITY

May 2012

Dr. Megumi Hosoda

Dr. Howard Tokunaga

Terry Foushee
Department of Psychology

Department of Psychology

Saint Agnes Medical Center 


\begin{abstract}
THE EXAMINATION OF THE MODERATING VARIABLES OF JOB EXPOSURE AND NEED FOR COGNITION ON THE EFFECTS OF TYPE OF JOB PREVIEW ON PRE-HIRE OUTCOMES
\end{abstract}

by Ashley Jo Hacnik

Although research on realistic job previews (RJP) has shown that RJPs produce positive individual and organizational outcomes, little is known of whether the characteristics of individuals change such positive relationships. Therefore, the current study extends previous research on RJPs by examining 163 nursing interns and registered nurses on how two individual characteristics -- previous job exposure and Need for Cognition (NFC) -- moderate the relationship between type of job preview and perceived job attractiveness, a job acceptance decision, and perceived organizational honesty. Results showed that those with no previous job exposure and those low in NFC rated the job as more attractive, accepted the job more often, and rated the organization as more honest when presented with a traditional job preview (TJP) than when presented with a realistic job preview (RJP) . The opposite patterns were found for those individuals who were high in NFC. Results of the present study indicate that organizations need to take into account type of job preview and individual characteristics for successful recruitment efforts. Theoretical and practical implications of the study are discussed. 


\section{ACKNOWLEDGEMENTS}

I would like to start by expressing my sincere gratitude to Dr. Megumi Hosoda for all her support and guidance in completing this thesis. This work would not have been accomplished without her constantly pushing me to make this paper better.

I also want to acknowledge Dr. Howard Tokunaga for all his support and advice in completing this work. Without his advice the results sections never would have been completed.

I would also like to give a special thanks to my wonderful parents for their support and encouragement through all of my educational endeavors. You both are the reason that I am so focused and motivated to be the best person that I can be.

Lastly, I would like to thank my amazing husband Daniel for always being a source of strength and encouragement. Without his unconditional support, this work would not have been completed. You are and always will be my better half. 


\section{TABLE OF CONTENTS}

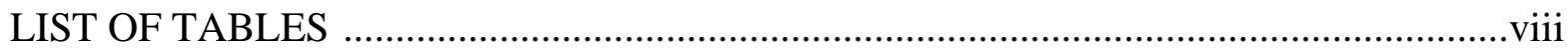

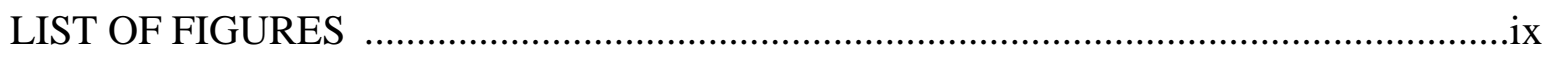

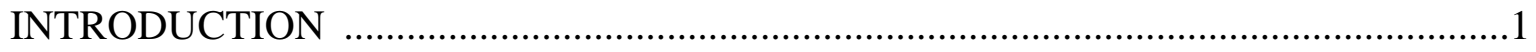

Uses of RJPs

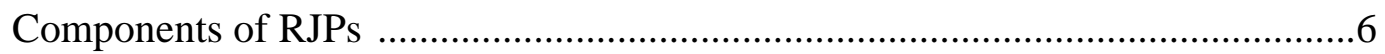

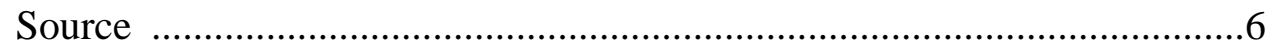

Message Content .......................................................................

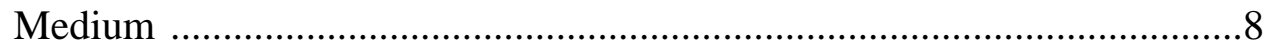

Effects of RJPs .................................................................................... 10

Pre- Hire Outcomes ..........................................................................10

Post- Hire Outcomes .........................................................................13

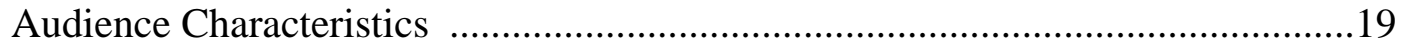

Previous Job Exposure ...............................................................19

Need for Cognition .........................................................................23

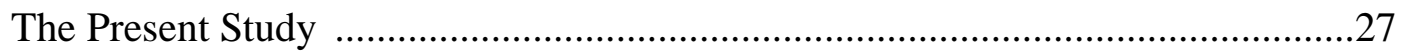

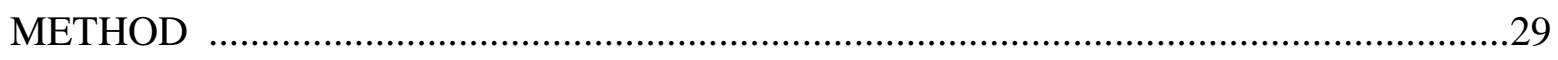

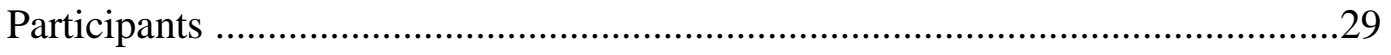

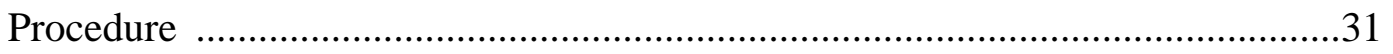

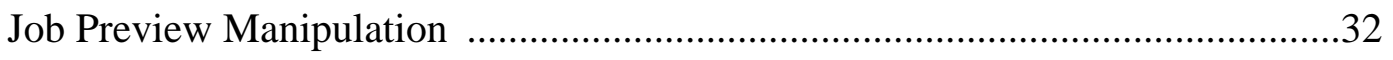

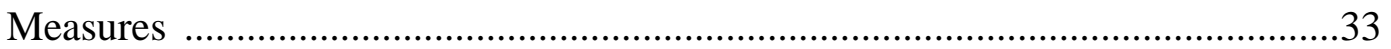

Job Attractiveness .........................................................................33 
Job Acceptance Decision ..................................................................33

Perception of an Organization’s Honesty ..............................................33

Need for Cognition .......................................................................34

Previous Job Exposure .................................................................34

Manipulation Check ............................................................................34

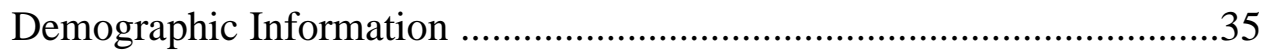

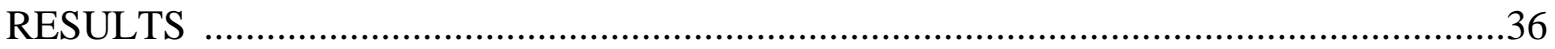

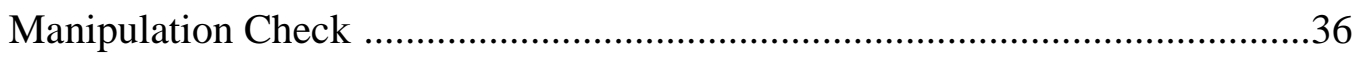

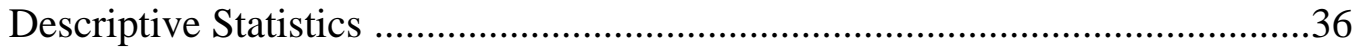

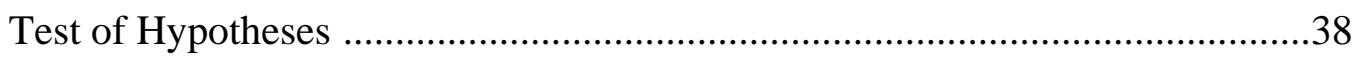

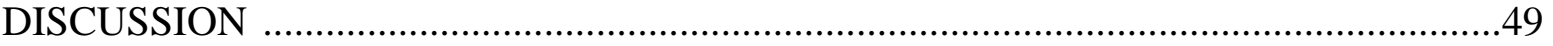

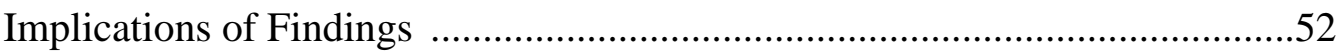

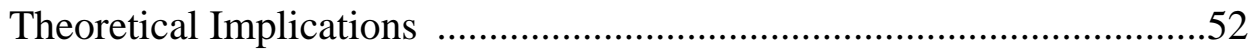

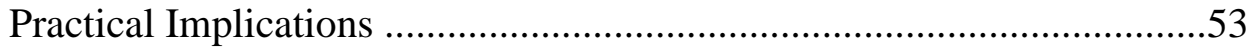

Strengths, Limitations, and Future Research ..............................................55

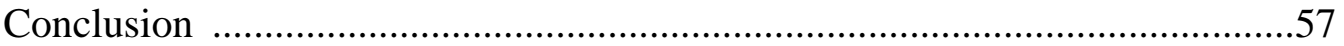

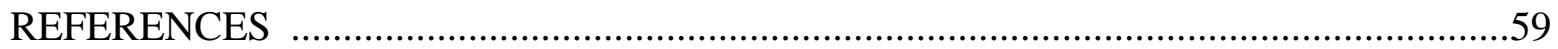




\section{LIST OF TABLES}

Table 1. Demographic Characteristics of Participants .................................................30

Table 2. Correlations Among Measured Variables .........................................................37

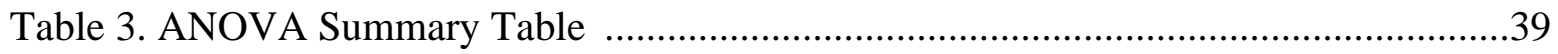

Table 4. Frequency Distribution of Job Acceptance as a Function of Job Exposure

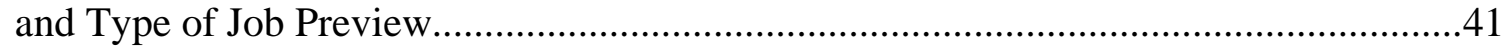

Table 5. ANOVA Summary Table ........................................................................42

Table 6. Hierarchical MRC Table for the Variable Job Attractiveness .............................44

Table 7. Frequency Distribution of Job Acceptance as a Function of NFC and

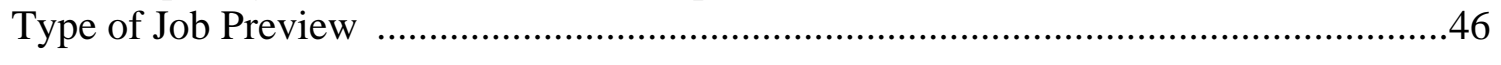

Table 8. Hierarchical MRC Table for the Variable Perception of Organizational Honesty..48 


\section{LIST OF FIGURES}

Figure 1. Job attractiveness as a function of type of job preview and previous job exposure

Figure 2. Mean perception of organizational honesty as a function of type of job preview and previous job exposure

Figure 3. Job attractiveness as a function of type of job preview and NFC

Figure 4. Perception of organizational honesty as a function of type of job preview and NFC .48 


\section{Introduction}

Organizations are increasingly and justifiably concerned with the effectiveness of their recruitment messages, especially in a time plagued with high unemployment rates and increased competition for skilled workers (Green \& Brooke, 2001). Because of the importance of the recruitment process, attention given to the topic of employee recruitment by researchers has increased considerably in recent years (Breaugh, Macan, \& Grambow, 2008). With the unemployment rate as high as 9.6\% in the United States, organizations need to make sure that they are attracting the best applicants to fill their open positions (U.S. Bureau of Labor Statistics, 2010). In order to attract the highest quality applicants, organizations often present a rosy picture of the company and job to applicants while deemphasizing their negative aspects. This creates an inflated picture of the organization and job for the applicants, which is likely to create problems when they actually face the realities of the job after they are hired. Research has indeed demonstrated that overemphasizing the positive attributes while minimizing the negative attributes of a job may lead to negative employment outcomes such as job dissatisfaction, dissatisfaction with the organization, absenteeism, and turnover (Lee, Ashford, Walsh, \& Mowday, 1992).

One way to combat this problem is by using realistic job previews (RJPs). RJPs, in the most basic sense, are job descriptions that present both positive and negative jobrelated information to applicants (Phillips, 1998). RJPs are designed to provide an accurate and realistic picture of the job to prospective applicants. There are four major

components of an RJP that could influence its usefulness; source of a message (who will 
present), message content (what to present), medium used (how to present), and audience (applicant) characteristics (Popovich \& Wanous, 1981). Although research on RJPs has focused on the source of a message, message content, the medium used, and audience characteristics have received relatively little attention (Adeyemi-Bello \& Mulvaney, 1995). Psychological, mental, and emotional characteristics of applicants should be examined because they can influence how an individual processes the information presented in an RJP (Adeyemi-Bello \& Mulvaney). Thus, the success of an RJP might be contingent upon an individual's interpretation of the information presented in the RJP. The current research sought to explore this important area by examining the effects of individual differences on the interpretation of RJP information. Specifically, the present study examined the moderating impact of job exposure and a social-cognitive trait, Need for Cognition (NFC), on the relationship between the type of job preview and job attractiveness, the job acceptance decision, and the perception of organizational honesty. The following sections provide research findings pertaining to (a) how RJPs are used, (b) the major components of RJPs, (c) the effects of RJPs, and (d) individual characteristics that have been shown to influence information processing (i.e., previous job exposure and a social-cognitive personality trait of NFC).

\section{Uses of RJPs}

There are a number of different uses of RJPs. In many instances, RJPs are used as “screening devices,” which allow applicants to assess whether they can meet an organization's needs as well as whether the organization is capable of meeting their needs (Wanous, 1973). RJPs can be used to attract the best fitting applicants for a particular job 
and organization (Premack \& Wanous, 1985). This is known as self-selection and is the process whereby applicants assess their skills and abilities in relation to the demands of the job and the organization (Premack \& Wanous). If applicants do not feel that they are a good match with the organization or the job, they are expected to withdraw from the selection process (Saks, Wiesner, \& Summers, 1994). As a result, the applicants who are the best fit to perform the tasks and realistically understand the demands of the job should remain in the candidate pool.

However, because previous research indicates that RJPs might turn away otherwise qualified applicants due to the inclusion of negative information; it has also been proposed that RJPs be provided only during an orientation process after a job offer has been accepted (Saks et al., 1994). In this instance, the RJP is used as a method for individuals to learn more about the job so they are better able to cope with what is to come rather than as a screening device or a self-selection tool. For example, Susko and Breaugh (1986) conducted a study in which 28 applicants for an inventory taker position were either presented with a written RJP (experimental condition) or not given anything. The RJP included information on both positive and negative job attributes of the position. Participants in the experimental condition received the written RJP before the final interview and an oral RJP during the standard training. Among those who were in the RJP condition, only four out of 15 applicants rejected the job offer. For the no-RJP condition, none of the 13 applicants rejected the job offer. Although applicants who received the RJP were more likely to self-select out of the position, the RJP had a positive impact on those who accepted the job offer. That is, they tended to perceive the 
organization as being more straightforward and truthful, reported higher levels of satisfaction with the position and a greater ability to cope with job demands, and were less likely to voluntarily leave the organization compared to applicants who did not receive the RJP (Susko \& Breaugh).

The "work of worry" effect has been used to explain the above findings (Meglino \& DeNisi, 1987; Meglino, DeNisi, Youngblood, \& Williams, 1988; Pitt \& Ramaseshan, 1995). The "work of worry" effect comes from research conducted by Janis (1958) with medical patients about to undergo difficult medical procedures. When patients received a preview of the procedure and were told how much pain would be involved, these patients experienced a modest amount of trepidation and concern. Interestingly enough, patients who received the realistic preview also tended to recover more rapidly with fewer medical complications compared to patients who did not receive the preview. The realistic information given to patients about the medical procedure they were about to undergo allowed them to develop coping mechanisms that permitted them an easier adjustment to the actual procedure. In the workplace context, the "work of worry" effect refers to the fact that information that may evoke worry or concern is likely to be used by employees to cope with the negative aspects of the job (Pitt \& Ramaseshan, 1995). Certain aspects of a job might provoke distress when they are described to potential employees in detail before they actually begin the job. Giving realistic job information can actually help to ease anxiety about a new job by allowing them to develop ways of coping with negative aspects of the job. As a result, employees presented with the 
negative information before beginning the job should report less dissatisfaction after they are hired (Pitt \& Ramaseshan).

RJPs are also used to lower an applicant's initially inflated expectations (Buda \& Charnov, 2003). Individuals often have inaccurate expectations about job tasks or the environment where they would potentially be working (Wanous, 1973). For this reason, RJPs have been used as an approach to alter applicants’ unrealistic expectations (Adeyemi-Bello \& Mulvaney, 1995). Porter and Steers (1973) define the met expectations hypothesis as the discrepancy between what individuals encounter on the job in the way of positive and negative experiences and what they expected to encounter. According to the met expectations hypothesis, by lowering individuals' initial expectations through RJPs, the discrepancy will be reduced, thus, it is expected that they will report higher levels of job satisfaction because their subsequent experiences are comparable to their lowered expectations (Dilla, 1987). A number of studies have supported this assertion and have also found that those receiving an RJP had lower and more realistic expectations about the job compared to candidates who received a preview containing only positive information (Avner, Guastello, \& Aderman, 1982; Colarelli, 1984; Dean \& Wanous, 1984; Irving \& Montes, 2009; Dugoni \& Ilgen, 1981; Phillips, 1998; Saks \& Cronshaw, 1990; Wanous, Poland, Premack, \& Davis, 1992). Given these findings, it is suggested that RJPs be used when applicants can be selective, have unrealistic expectations, and/or might have trouble coping with the demands of the job (Breaugh, 1983). 


\section{Components of RJPs}

As mentioned earlier, there are four major components of an RJP that could influence its usefulness; the source of a message, message content, medium used, and audience characteristics (Popovich \& Wanous, 1981).

Source. One important aspect in the presentation of RJPs is the source from which information is presented. Research shows that recruiting information should be presented from a source that is viewed as credible because source credibility is a factor capable of changing a candidate's attitude toward the position and the organization (Breaugh \& Starke, 2000; Adeyemi-Bello \& Mulvaney, 1995). Expertise and trustworthiness of a source have also been shown to lead to a recruiting message's believability (Breaugh \& Starke). When presented with a written RJP, applicants are more likely to perceive a recruiter as more trustworthy, knowledgeable, and credible compared to those who received only general job information verbally during the interview (Saks, 1989). Saks and Cronshaw (1990) also showed that participants who received an oral RJP from an interviewer had more positive impressions of the interviewer and the organization's honesty than those in both the written RJP and the control groups.

Irving and Coleman (1997) examined the effects of message source on job attractiveness and job choice. Each participant reviewed a traditional job preview (TJP) that contained only positive information and an RJP that contained both positive and negative information from either a trained recruiter or a person currently performing that

job (an incumbent). Results showed that more participants chose the RJP job, regardless 
of the source from which they received the preview. This finding is contrary to previous research on RJPs which found that negatively previewed jobs resulted in lower job acceptance rates (Saks et al., 1994; Suszko \& Breaugh, 1986; Wiesner, Saks, \& Summers, 1991). Results also demonstrated that $59 \%$ of the participants in the RJP condition who accepted the job indicated that the honesty of the information source was the reason for their choice, while $84 \%$ of those in the TJP condition who accepted the job indicated that the attractiveness of the position was the reason for their choice. This finding is worthy of mention because it indicates that type of job preview, not the source of the message, made a difference in job choice. Their results suggest that the source of a recruitment message may not matter, but the nature of a job preview does. It is more beneficial to present both negative and positive information to job applicants. Consequently, the perceived honesty of the information presented in the RJP might affect participants' level of attraction to the job and their job choice.

Message content. The message content that is presented in an RJP has also received considerable attention because this information is likely to be used by potential applicants to make a decision about a job (Bretz \& Judge, 1998; Wanous, 1989; Buda \& Charnov, 2003; Popovich \& Wanous, 1981). One might suppose that the only way to construct an accurate RJP would be to include mostly descriptive material (e.g., starting salaries, average length of time to a promotion, hours of work). Another choice in deciding the content of a message is the amount of positive and negative information included in an RJP. Negative information gains more attention and scrutiny from applicants than positive information (Buda \& Charnov). Cacioppo and Berntson (1994) 
describe the negativity bias as the tendency by which humans pay more attention to and give more weight to negative rather than positive experiences or information. One consequence of the negativity bias is that attitudinal and behavioral expressions are more strongly influenced by negative inputs rather than by positive inputs, resulting in greater responsivity to the negative inputs than to the positive inputs (Cacioppo \& Berntson).

The amount of negative information presented in an RJP has been shown to play a critical role in an applicant's perceptions of an RJP (Bretz \& Judge, 1998). For example, by manipulating the amount of negative job information, Bretz and Judge examined the amount of weight applicants placed on negative information and the impact it had on their attraction to a job. Results showed that there was a significant negative relationship between the amount of negative information conveyed and applicants' attraction to the job. More specifically, the more negative information included in an RJP, the less applicants perceived the job to be attractive. Furthermore, they found that highly qualified applicants tended to pursue jobs where the organization included some negative information in its recruitment message compared to those who were less qualified for the position. Overall, previous research indicates that in terms of message content, it is beneficial to add negative information to a job preview in order to attract high quality applicants, but that too much negative information might deter them from being attracted to the job.

Medium. There are several different ways to deliver RJP information with written job descriptions, face-to-face communications, and written pamphlets or booklets being the most prominent (Wanous, 1989). In their meta-analysis, Premack and Wanous 
(1985) found that the type of medium used to present an RJP significantly moderated the relationship between the RJP and job performance. They found that audio-visual RJPs were positively related to job performance, while written RJPs were to some extent negatively related to job performance. One possible explanation for these findings is that RJPs are considered a type of persuasive communication (Popovich \& Wanous, 1981) and that live and videotaped messages are more persuasive than written messages (Eagly \& Himmelfarb, 1978). Saks and Cronshaw (1990) examined the effectiveness of an oral RJP presented by an employment interviewer compared to a written RJP. They found that the oral RJP tended to elicit more positive feelings of the job and the organization than the written RJP.

Phillips (1998) conducted a meta-analysis on the effects of the communication medium of RJPs on various outcomes including attrition from a recruitment process, the level of initial expectations, the accuracy of initial expectations, a climate for honesty, job satisfaction, organizational commitment, turnover, and job performance. The medium of RJPs included written, verbal, and videotaped. Results of the meta-analysis showed that only verbal RJPs were positively associated with job satisfaction. Verbal RJPs were also associated with the greatest reduction in turnover, followed by written RJPs. Videotaped RJPs had the strongest positive relationship with performance. Written RJPs were associated with a small reduction in turnover and a slight decrease in attrition from the recruitment process. One possible explanation for these findings is that in face-to-face communications, the active processing of information is more likely to happen (Daft \& Lengel, 1986). Hence, when presented with a verbal RJP, people are likely to process 
information more deeply, which is likely to create a more enduring attitude change, leading to positive organizational outcomes than when presented with a written RJP. Results from this meta-analysis show that overall, mean effect sizes are consistently greater for videotaped and verbal RJPs than for written RJPs. Given these findings, Phillips concluded that even though written RJPs were most frequently used, they were actually the least effective of the three media. Considering that much of the research on RJPs have mainly used written RJPs, one reason for the findings that RJPs are sometimes not effective is probably because of the heavy use of written RJPs.

\section{Effects of RJPs}

The effects of RJPs have been examined in terms of both pre-hire and post-hire outcomes (Saks \& Cronshaw, 1990). Pre-hire outcomes include outcomes such as selfselection, job acceptance rates, job attractiveness, and perception of organizational honesty. In contrast, post-hire outcomes include job performance, turnover, and job satisfaction.

Pre-hire outcomes. As mentioned earlier, research has demonstrated that selfselection can be influenced by the presence of RJPs (Premack \& Wanous, 1985). If applicants do not feel they are a good match with the organization or the job, they are expected to withdraw from the selection process (Saks et al., 1994). If the organization provides RJPs about a job, applicants should have a more realistic and accurate picture of what the job entails (Breaugh \& Starke, 2000), which allows them to make a more informed decision as to whether to pursue the job (Bretz \& Judge, 1998). The information given in an RJP is also likely to increase an individual's accuracy in 
assessing whether he or she has skills and abilities necessary to perform the tasks associated with a job successfully (Gardner, Foo, \& Hesketh, 1995). As a result, applicants who are the best fit to perform the tasks and realistically understand the demands of the job should remain in the candidate pool.

A distinction needs to be made between self-selection and job acceptance (Saks et al., 1994). Research examining self-selection often uses job acceptance as an indication of self-selection when they are actually two separate things (Saks et al.). Job acceptance only measures whether or not an applicant accepts the job, while self-selection involves the perceived match between an applicant's needs and the ability of an organization to fulfill such needs (Saks, Wiesner, \& Summers, 1996).

In their meta-analysis, Premack and Wanous (1985) found that an RJP resulted in an increase in the number of candidates who withdrew from a recruitment process compared to those who did not receive the RJP. However, based on their results, it could not be determined if candidates had made a self-assessment based on the RJP or selfselected out of the process because their meta-analysis only used raw drop-out rates between the RJP and control groups, instead of assessing what individuals expected and what they thought the organization could give them. Research by Saks et al. specifically took into account the difference between self-selection and job acceptance. Results indicated that approximately $86 \%$ of the participants who received an RJP reported a match between their needs and what they expected from the organization. Self-selection is said to be evident when a candidate's needs and expectations are congruent (Saks et al.). Given such a high percentage, Saks et al. concluded that the RJP resulted in a self- 
selection out of the recruitment process by the applicants who did not have a match between what they expected from the organization and what they actually received from the organization.

Irving and Coleman (1997) explored the premise that job applicants would select the job that is deemed most attractive. A total of 134 students were given two job previews, a TJP and an RJP. Participants read both job previews and rated the attractiveness of the job, source credibility, and their job choice intentions. The researchers found that the majority of participants rated the RJP as more attractive and actually selected the job that contained the RJP over the job that only stated the positive aspects of the position (TJP).

Earlier research has reported that RJPs reduce the number of job offers accepted (Saks et al., 1994; Suszko \& Breaugh, 1986; Wiesner et al., 1991). For example, Saks et al. had 138 undergraduate students participate in a job choice exercise. Participants in one group were given a TJP and participants in another group were given a written RJP for the same job. The third group was presented with both the TJP and the RJP. When presented with both types of job previews, participants accepted the job depicted in the TJP significantly more than the job depicted in the RJP. However, there was no difference between those who were presented with the RJP and those who were presented with the TJP in job acceptance. These findings indicate that using both TJPs and RJPs together may decrease the number of people who will actually choose the job described in the RJP.

Since RJPs include some negative information, it is often believed that individuals 
are likely to rate the depicted job and the organization offering the job as less attractive (Bretz \& Judge, 1998; Saks et al., 1994, 1996). Saks and Cronshaw (1990) specifically examined RJPs and their impact on job attractiveness. Their study utilized data gathered from 60 undergraduate students who were randomly assigned to one of three experimental conditions: a verbal RJP presented to job applicants by an employment interviewer during an employment interview, a written RJP given to job applicants to read before an employment interview, and a control condition that gave applicants general job information by an interviewer during an interview. The position of hotel desk clerk was used. The oral and written RJP contained the exact same information about both the positive and negative features of the hotel desk clerk's job. For the control condition, the general job information was equal in length to the information in the RJP but contained only information that was general in nature and did not discuss what one might expect from the job or the organization. Results showed that the participants who received the oral RJP from the interviewer had more positive impressions of the interviewer and the organization's honesty than those in both the written RJP and the control groups. This study provides strong implications for the idea that oral RJPs may actually increase job and organizational attractiveness when presented by an actual member of the organization. Finally, results of a meta-analysis (Phillips, 1998) also show that in general, RJPs are related to lower levels of attrition from a recruitment process and lower initial expectations compared to the use of TJPs.

Post-hire outcomes. Research has also identified several positive post-hire outcomes related to the use of RJPs. The effect of presenting RJP information on 
subsequent job performance has been examined, however, results are mixed. For example, Dean and Wanous (1984) hypothesized that RJPs would reduce turnover and increase job performance. Their study used a total of 249 newly hired bank tellers and followed them for 43 weeks into their initial training and once in the position. Participants were randomly assigned to one of three groups; the first group received an RJP that contained both negative and positive information that was both specific and general pertaining to the position of a bank teller. The second group received only general information about the position of a bank teller, and the third group was a control group that received no preview. Job performance was measured eight weeks later, and results showed that there was no difference on performance among the three groups. One possible explanation for the lack of the differences in job performance across the conditions is that since participants went through extensive training on how to become a bank teller, this might have outweighed any effects that the RJP had on job performance.

In contrast, a laboratory study by Dilla (1987) found descriptive job previews, which contained information about a job position and the organization, to significantly influence the quality of performance. A total of 132 undergraduate students were presented either a descriptive, prescriptive, or control preview. The descriptive job preview focused on the nature of the job which included both positive and negative aspects of the job. This is similar to what would be found in an RJP. The prescriptive preview contained suggestions to help them cope with the job as well as general job information. The control preview only included general job information without any information on the negative aspects of the job. Participants were presented with the job 
of computing prices for different catalog merchandise. Participants' performance was measured by using the total number of errors made when reporting prices. Participants who received the descriptive preview had the highest level of performance, followed by those in the prescriptive preview, then those in the control preview. This study demonstrates that future job incumbents need to be provided not only with the information on how to do the job, but also with the information about the favorable and unfavorable parts of the job since this is likely to lead to better performance.

Although the above findings indicate that the effects of RJPs on performance are mixed, a meta-analysis by Phillips (1998) suggests that RJPs slightly increase job performance. Performance tends to increase most when RJPs are given audio-visually, followed by verbal RJPs, and then written RJPs.

Turnover is also an outcome variable that has received much attention in the RJP literature (Saks et al., 1994; Suszko \& Breaugh, 1986). Rynes (1991) proposes several different hypotheses to explain why RJPs lead to lower turnover. The self-selection hypothesis suggests that RJPs can positively affect how long a person will stay with the organization because by giving applicants realistic information about the job, they are better able to determine whether the job will likely match their needs. The commitment hypothesis proposes that when given all the information necessary to make informed job choices (i.e. realistic job information), those who decide to enter the organization are likely to be committed because they are able to make a more informed choice. The coping hypothesis states that by providing new employees with realistic information about the job, they are able to develop strategies to cope with the demands of the new 
job. Finally, the met expectations hypothesis suggests that RJPs will actually lower an applicant's initial inflated expectations, which can cause them to experience increased job satisfaction, which can also lead to reduced voluntary turnover.

Research examining the effects of RJPs on turnover has found that the use of RJPs has mixed effects on turnover. For example, Hom, Griffeth, Palich, and Bracker (1999) conducted research with newly hired nurses and found that the group that was presented with an RJP experienced lower turnover compared to the group that received a TJP. In this study, turnover for those who received the RJP was two and a half times lower than that of the control group. Another study presented an RJP to a group of participants after they joined the organization but before they began reporting to the organization (Ilgen \& Seely, 1974). In this study, the control group experienced two times more turnover than the RJP group experienced. Both of these studies found large reductions in turnover for the RJP group when compared to the control group. Similarly, Collarelli (1984) used applicants for bank teller positions in a field study. Participants were either presented with an RJP from an incumbent, an RJP in the form of a brochure, or no job preview at all (control group). Those in the control group experienced more than twice the turnover than those who received the RJP from the incumbent. However, there was no difference in turnover between the group that received the RJP in the form of a brochure and the control group.

However, findings from Reilly, Brown, Blood, and Malatesta (1981) contradict with the above findings. Applicants for the position of telephone representative either saw an RJP film, visited the job, or received no job information prior to accepting a job 
offer. There were no differences in turnover among these three groups after six months on the job. Interestingly, at no point during the six-months after accepting the job was turnover lower for the preview groups than for the control group.

Results of the meta-analysis by Philips (1998) show that RJPs have negative effects on turnover, but the effect sizes differ depending on the medium used to present RJPs. Verbal RJPs are the most effective at reducing turnover, followed by written RJPs, with videotaped RJPs being the least effective.

Several studies have examined the relationship between RJPs and job satisfaction. As described earlier, the met expectations hypothesis has also been used to explain how RJPs might be related positively to job satisfaction. Hom et al. (1999) presented newly hired nurses with either an RJP or a TJP and found that the RJP led to an increase in met expectations as well as higher job satisfaction. Suszko and Breaugh (1986) found that applicants for the job of inventory taker who were given an RJP reported significantly higher levels of job satisfaction than those in the control group. However, Dilla (1987) did not find that RJPs were positively related to job satisfaction.

One possible explanation for these mixed results might be because participants from study to study differed in the length of time they were employed. For example, Hom et al. (1999) asked nurses about their job attitudes three weeks after they entered the organization, whereas Suszko and Breaugh (1986) waited six weeks. Dilla (1987), on the other hand, had participants perform one work session before asking them to rate their satisfaction; this could explain why Dilla did not find support for the positive effect of RJPs on job satisfaction. Since Hom et al. and Suszko and Breaugh measured job 
satisfaction after a longer amount of time spent in the position, their results appear to be more valid. This would mean that by meeting applicants' expectations before they begin the job through RJPs, they are likely to have higher job satisfaction once hired. However, results from Phillips' (1998) meta-analysis show that RJPs in general are unrelated to job satisfaction and organizational commitment.

Overall, the results for the effects of RJPs on pre-hire outcomes have been positive in that applicants are able to select the job that best fits their needs, rate the job and the organization as more attractive, and tend to accept job offers more often. On the other hand, the effects of RJPs on post-hire outcomes have been mixed. Some studies have found that RJPs reduce turnover and increase job satisfaction and job performance, while others have not. Phillips (1998) shows that overall, RJPs reduce turnover, but are unrelated to job attitudes (e.g., job satisfaction, organizational commitment). Phillips argues that the effect sizes of RJPs actually depend on many variables including the medium of RJPs, timing of RJPs, and research settings. One main reason for the inconsistent findings on the effects of RJPs on outcome variables (e.g., turnover, job satisfaction, performance) may be due to the lack of attention to individual difference variables. Considering that the effectiveness of RJPs is dependent on several variables, it would be reasonable to assume that RJP effectiveness is also dependent on individual characteristics (e.g., personality traits, job experience). Yet, there has been relatively little research done on individual characteristics and how they influence the effectiveness of RJPs. 


\section{Audience Characteristics}

As mentioned earlier, audience characteristics are one of the components of RJPs that has received the least amount of research attention (Adeyemi-Bello \& Mulvaney, 1995). An examination of the emotional, mental, and psychological characteristics of individuals is important because they might influence an individual's ability to process information presented in an RJP (Adeyemi-Bello \& Mulvaney) and the success of the RJP might be contingent upon the individual's interpretation of information presented to him or her in the RJP. Since the success of the RJP might be contingent on how the individual interprets the information, researchers need to pay more attention to audience characteristics. Individual characteristics that have been studied to influence information processing are previous job exposure and a trait of Need for Cognition (NFC). The sections below present a brief review of the literature on the effects of these characteristics on the effectiveness of RJPs.

Previous job exposure. Previous job exposure has been researched as one of the possible moderators of the relationship between RJPs and job attractiveness (Meglino, DeNisi, \& Ravlin, 1993). Job exposure is defined as an individual's experience with a particular job (Meglino, et al., 1993). It is important to note that there is not a clear distinction made between job exposure and job experience in the literature and that the two terms seem to be used interchangeably (Meglino, Ravlin, \& DeNisi, 2000). However, job experience is defined as either having done the job previously or having had previous contact to others doing the job (Meglino et al., 1993). 
Meglino et al. (2000) have argued that individuals who have more exposure with a job place a greater emphasis on the negative information contained in an RJP than those who do not have previous job exposure. For example, Lichtenstein, Slovic, Fischhoff, Layman, and Combs (1978) showed that those who have had direct exposure to noxious events tended to exaggerate the frequency of those events. Specifically, they found that a sample of college students and physicians who have had a personal experience with a certain disease actually overestimated the likelihood of dying from that disease when compared to individuals who have had no direct experience with the disease. Applying these findings to an organizational selection context, it is reasonable to assume that those applicants with previous exposure to an actual job are likely to place a greater emphasis on negative information contained in an RJP than those individuals without such previous job exposure.

Meglino, Ravlin, and DeNisi (1993) conducted a study with correctional officers. They argued that individuals with previous job exposure were more likely to have an accurate and comprehensive view of the job compared to those who did not have previous job exposure. They hypothesized that those with more exposure would accept the job in an RJP more than those who do not have previous exposure. Yet, they found that the RJP resulted in a lower rate of job acceptance among applicants with previous exposure and a higher rate of acceptance among those with no previous job exposure. Consistent with Lichtenstein et al.'s (1978) findings, they also found that those individuals with previous job exposure placed more emphasis on the negative information in the RJP compared to those with no exposure. 
In addition, Meglino et al. (2000) re-examined nine past RJP studies and found that individuals who have had previous job exposure tended to accept a job at a lower rate (specifically, a $9.8 \%$ decrease in job acceptance rates) after receiving an RJP compared to those who have not had previous exposure to the job. These researchers also reported that individuals with little to no previous exposure to a job tended to emphasize the positive aspects of the RJP and showed higher acceptance rates.

RJPs are thought to be more useful if applicants lack a realistic perspective of a job than those with previous job exposure to that job (Reilly et al., 1981; Saks, 1989). Inexperienced applicants are thought to be more impressionable because they are likely to have fewer job experiences (Breaugh, 1983). For this reason, it would be expected that applicants with little job exposure would have a less realistic perspective of a job. Hom et al. (1999) have also suggested that applicants with little or no exposure in the respective field might benefit more from RJPs because their inaccurate expectations will become more aligned with the reality of the job with the presence of an RJP.

As noted earlier, Bretz and Judge (1998) examined applicant quality. They administered surveys containing hypothetical scenarios that manipulated job characteristics and recruiting processes to graduate and undergraduate students enrolled in a professional degree program. One component of applicant quality was work experience. In contrast to Meglino, DeNisi, and Ravlin (1997) findings, they found that applicants with less work experience placed significantly more weight on negative information than they did for positive information. This was found even when applicants were highly qualified but had less experience. Based on these findings, it was concluded 
that experienced applicants were less likely to have a negative reaction to the information presented in an RJP. This finding is in keeping with the idea that more experienced applicants are not likely to be impacted much by the negative information included in an RJP. This indicates that job exposure might play an important role in how applicants view the negative information presented in an RJP and how they react to such negative information. Since the findings of Bretz and Judge (1998) are in complete opposition with Meglino et al.'s (1997) findings it is important to look at the methodologies that both studies used. Bretz and Judge (1998) gave hypothetical scenarios to students who were not currently job incumbents, while Meglino et al.'s study used actual correctional officers who had previous experience with the position described in the RJP. Considering the variable of interest is previous exposure, it seems Meglino et al.'s findings might be more generalizable.

The present study seeks to add to the literature on RJPs through the inclusion of audience characteristics. This study examines the effects of RJPs on pre-hire outcomes. In keeping with previous research, this study investigates the most frequently examined pre-hire outcomes: attractiveness of the position, a job acceptance decision, and perception of an organization's honesty (Phillips, 1998). Although these are the most frequently used pre-hire outcomes, there has been very little research done on the moderator variable of previous job exposure on the effect of RJPs on these pre-hire outcomes. 
Based upon the previous research, the current study hypothesizes that Hypothesis 1a: Previous job exposure will moderate the effects of type of job preview on job attractiveness such that those with no previous exposure to the job will rate the preview that contains only positive information (TJP) as more attractive than the preview that contains both positive and negative information (RJP). In contrast, those with previous job exposure will rate the RJP as more attractive than the TJP.

Hypothesis 1b: Previous job exposure will moderate the effects of type of job preview on a job acceptance decision such that those with no previous job exposure will accept the job more often when presented with the TJP than when presented with the RJP. In contrast, those with previous job exposure will accept the job presented with the RJP more often than the job presented with the TJP.

Hypothesis 1c: Previous job exposure will moderate the effects of type of job preview on the perceived honesty of an organization such that those with no previous job exposure will perceive the organization as more honest when presented with the TJP than when presented with the RJP. In contrast, those with previous job exposure will perceive the organization more honest when presented with the RJP than when presented with the TJP.

Need for cognition (NFC). Buda and Charnov (2003) argued that individuals differ in their ability and desire to exert cognitive effort when processing information. 
People also differ in their desire to engage in issue-relevant thinking when they form their attitudes (Cacioppo, Petty, \& Koa, 1984), and this is known as an individual's NFC. NFC has been defined as "an individual's tendency to engage in and enjoy effortful cognitive endeavors" (Cacioppo, Petty, Feinstein, \& Jarvis, 1996).

Individuals high in NFC are thought to seek, acquire, think about, and reflect on information in order to understand their environment (Cacioppo et al., 1996). When presented with stimuli or tasks requiring reasoning or problem solving, individuals high in NFC express more positive attitudes toward this process than those low in NFC (Cacioppo et al. 1996). Individuals high in NFC also spend more time processing messages regardless of how they are framed (Smith \& Petty, 1996). In contrast, those low in NFC are less likely to engage in careful processing and are more likely to be influenced by simple cues that allow evaluation without assessing the merits of the arguments presented. Indeed, studies show that as NFC decreased, people were more influenced by secondary attributes such as an endorser's attractiveness (Haugtvedt, Petty, \& Cacioppo, 1992) rather than by the quality of information provided.

Smith and Petty (1996) examined NFC and the processing of positively and negatively framed messages. Because negatively framed messages have been shown to require more processing, it was believed that individuals high in NFC would appreciate this information and would take the time to understand how the information fits in with their schema (Smith \& Petty). When the message was expected to be positively framed, but was actually negatively framed, participants high in NFC processed the message more extensively than participants who were low in NFC. It was also shown that 
participants low in NFC engaged in minimal message processing when the information confirmed their expectations but more processing when their expectations were not congruent with initial expectations. Those high in NFC tended to process the information the same whether the information was consistent with their expectations or not. These findings are important because most applicants/incumbents may not expect negative information in a job preview, and those applicants who differ in NFC might process information differently and consequently react differently when making career choices.

Buda and Charnov (2003) specifically examined NFC in relation to RJPs. The study examined the moderating effect of NFC on the processing of framed messages and source credibility during RJPs. Source credibility was manipulated by presenting half of participants with RJP information from current job incumbents (high credibility) and the other half of participants with RJP information from recruiters (low credibility). Two hundred undergraduate students completed the short form of the NFC scale and were subsequently given either a positively framed RJP or a negatively framed RJP for a management position. After reading the job preview, participants completed measures that assessed their initial expectations from the job and the organization, perception of the attractiveness of the job, and their willingness to accept a job offer. Individuals low in NFC had significantly lower expectations about the job than those high in NFC when they were presented with a negatively framed RJP. Buda and Charnov expected this result in part because individuals low in NFC would be less motivated to analyze the information in the RJP. 
These researchers also hypothesized that compared to those high in NFC, low NFC participants would be influenced by message framing (positive and negative) and source credibility. Consistent with their expectations, results demonstrated that when the RJP was presented by a low credibility source, those low in NFC rated their job attitudes significantly lower than those high in NFC, regardless of how the RJP was framed. However, when the RJP was presented by a highly credible source, those low in NFC rated their job attitudes significantly higher than those high in NFC when RJP messages were positively framed. But those high in NFC and low in NFC did not differ in their ratings when the RJP was negatively framed. Essentially, these findings indicate that when a low credibility source presents an RJP, those low in NFC have less favorable attitudes about the job regardless of how the RJP is framed. However, when a high credibility source presents an RJP, those low in NFC react positively only when messages are positively framed. In contrast, those who were high in NFC tended to rate the job with a negatively framed message as slightly more attractive than the same job with a positively framed message. Interestingly, individuals high in NFC did actually rate the job given by the low credibility source with more favorable attitudes than when the message was given by a highly credible source, regardless of whether the message was positively or negatively framed. These findings clearly indicate that those who differ in NFC process information differently. This present study incorporates the findings by Buda and Charnov (2003) and adds to the literature on the effects of NFC and type of job preview on job attractiveness, a job acceptance decision, and perceived honesty of the organization. 
The current study hypothesizes that

Hypothesis 2a: NFC will moderate the effects of type of job preview on job attractiveness such that those who are high in NFC will rate an RJP as more attractive than a TJP. In contrast, those who are low in NFC will rate the TJP as more attractive than the RJP.

Hypothesis 2b: NFC will moderate the effects of type of job preview on a job acceptance decision such that those who are high in NFC will accept the job more often when presented with the RJP than when presented with the TJP. In contrast, those who are low in NFC will accept the job presented with the TJP more often than the job presented with the RJP.

Hypothesis 2c: NFC will moderate the effects of type of job preview on perceived honesty of an organization such that those high in NFC will perceive the organization as more honest when presented with the RJP than when presented with the TJP. In contrast, those low in NFC will perceive the organization as more honest when presented with the TJP than when presented with the RJP.

\section{The Present Study}

RJPs have been used to prevent the undesirable outcomes (i.e. turnover, lower job satisfaction) that might result when someone has unrealistically high pre-employment expectations. Much of the literature has pointed to the fact that when applicants receive some form of an RJP, they will have more realistic expectations before committing to a 
job than those who do not receive such a preview. Only some of the past literature has pointed to individual audience characteristics, with an emphasis on previous job exposure. Yet much of the research on RJPs has shown mixed results with no clear understanding of how having past exposure to a job affects one's reactions when given an RJP. There is still much more research needed to gain a clearer picture of how RJPs work. The present study focuses solely on those who have previous exposure with the position of registered nurse. This study looks directly at the differences between registered nurses (individuals with previous job exposure) and nursing interns (individuals with no previous job exposure) on their reactions as a function of type of job preview (RJP and TJP). Furthermore, individuals process information differently. Despite this, the lack of research attention on this difference could be one reason for mixed results in the past RJP research. The present study seeks to provide insight into the effects of individual characteristics, specifically previous job exposure and NFC, on the effectiveness of recruitment messages in hopes to find a clearer understanding for the effects that RJPs have on recruiting efforts. 


\section{Method}

\section{Participants}

A total of 163 participants (141 female and 22 male) were recruited from a large Central California Hospital. Participants ranged in age from 21 years to 57 years old ( $M$ $=32.26, S D=8.47)$. The ethnic breakdown of the sample was $58.3 \%$ Caucasians $(n=$ 95), 16.6\% Asian ( $n=27), 11.0 \%$ African American $(n=18), 8.0 \%$ Latino/a $(n=13)$,

and $5.5 \%$ Other $(n=9)$. About $67 \%$ of participants were registered nurses $(n=108)$ and 33\% were nursing interns $(n=55)$. All of the registered nurses who partook in this study were employed at the time of data collection, working an average of 25.72 hours per week $(S D=19.05)$. Among the registered nurses, most had at least 7 years of experience $(M=7.25, S D=8.17)$. Thus, a typical participant of the present study was a thirty-five year old Caucasian female registered nurse, with at least 7 years of experience.

Demographic information is presented in Table 1. 
Table 1. Demographic Characteristics of Participants $(n=163)$

\begin{tabular}{|c|c|c|c|c|c|}
\hline Variable & & $n$ & $\%$ & $M$ & SD \\
\hline Age & & 163 & - & 32.26 & 8.47 \\
\hline \multicolumn{6}{|l|}{ Gender } \\
\hline & Male & 22 & $13.4 \%$ & & \\
\hline & Female & 141 & $86.5 \%$ & & \\
\hline \multicolumn{6}{|l|}{ Ethnicity } \\
\hline & Caucasians & 95 & $58.3 \%$ & & \\
\hline & Asian & 27 & $16.6 \%$ & & \\
\hline & African American & 18 & $11.0 \%$ & & \\
\hline & Latino/a & 13 & $8.0 \%$ & & \\
\hline & Other & 9 & $5.5 \%$ & & \\
\hline \multicolumn{6}{|l|}{ Job title } \\
\hline & Registered Nurse & 108 & $66.3 \%$ & & \\
\hline & Intern & 55 & $33.7 \%$ & & \\
\hline $\begin{array}{l}\text { Years of experience as } \\
\text { registered nurse }\end{array}$ & & 108 & & 7.25 & 8.17 \\
\hline $\begin{array}{l}\text { Average hours worked per } \\
\text { week }\end{array}$ & & 108 & & 25.72 & 19.05 \\
\hline
\end{tabular}




\section{Procedure}

Potential participants were first contacted through a hospital-wide email that was sent to all registered nurses and nursing interns, informing them of the study as to when and where the study would take place, and how they could participate. Fliers were also posted throughout the medical center, in break rooms, and on employee-sponsored bulletin boards to solicit participation. The lead investigator also walked throughout the hospital to solicit participation from registered nurses and interns.

Participants were scheduled to complete the questionnaire as it fit their schedule. Once participants arrived at the designated place, they were first presented with a consent form. They were then asked to read and sign the consent form if they agreed to participate in the study. The principal investigator then read aloud the instructions for the study. After the instructions, half of the participants received an RJP and the other half received a TJP of the job description. The TJP was the standard job description the organization handed out for the position of registered nurse. It included the position requirements, a brief summary of the position, as well as the knowledge, skills, and abilities required to perform the job. The RJP contained the exact same information as the TJP with the addition of negative job-related information. They were then asked to read the job preview independently. After being given time to read the job description, participants were then given a questionnaire to complete. In the questionnaire, participants were asked to rate (a) the attractiveness of the job presented in the job preview, (b) their acceptance decision, and (c) perception of the honesty of the organization. They then completed a personality measure and provided demographic 
information. Questionnaires were returned to the researcher upon completion. When they were returned, each participant was then handed a detailed description of the hypotheses, expected outcomes, and contact information should they have any questions or concerns.

\section{Job Preview Manipulation}

Type of job preview was manipulated by creating two different job previews; the RJP and the TJP. Both the RJP and the TJP contained job task, knowledge, skills, and abilities (KSA) statements for the position of registered nurse, a summary of the position and current qualifications, all of which were taken from the O*Net website (2010). The RJP contained positive, negative, and neutral job information. The positive information was presented first and is in keeping with the recommendations of Buda \& Charnov (2003), and Popovich and Wanous (1981). The TJP contained all of the same information presented in the RJP, with the exception of the negative statements. The negative job information was obtained from interviews that were conducted with a group of 35 registered nurses and a recruiter for the hospital. The recruiter asked the nurses to give two statements related to the negative aspects of the position of registered nurse. There were a total of 86 statements given. The recruiter and the principal investigator then created themes based off the different statements given. These themes were then narrowed down into 11 negative statements for the position of registered nurse, and were included in the RJP. 


\section{Measures}

Job attractiveness. Although prior research in general has assessed job attractiveness using a single item (e.g.; Wiesner, Saks, \& Summers, 1991; Young, Rinehart, \& Heneman, 1993), the current study used five items to assess overall job attractiveness. Three items were from a study by Saks et al. (1994). Two additional questions, taken from a study by Bretz and Judge (1998), were asked which originally measured organization attractiveness. For the purposes of this study, the questions were changed to reflect job attractiveness. Sample items are "This job is attractive to me" and "I am interested in learning more about this position.” Each participant’s attractiveness of the job was determined by obtaining his or her mean rating for all five job attractiveness items. These items were measured using a 5-point Likert type scale ranging from 1 (strongly disagree) to 5 (strongly agree). Cronbach’s alpha coefficient for the five items is .98 , suggesting good internal reliability of the scale. The higher the scores, the more attractive the job was rated.

Job acceptance decision. In order to assess whether applicants would be willing to accept a job offer, one item from Saks et al. (1994) was used. The item used was "If offered the job, I would accept.” This item was assessed by choosing “yes” or “no.” This variable was coded as $1=$ yes and $2=$ no.

Perception of an organization's honesty. Two items were used in order to assess how honest the organization was perceived to be. These two items are "This organization is honest with their employees” and "This organization has integrity.” These items were measured using a 5-point Likert type scale ranging from 1 (strongly disagree) to 5 
(strongly agree). There is a positive relationship between these items, $r(161)=.96, p<$ .01. Higher scores indicate that participants perceived the organization to be more honest.

Need for cognition (NFC). NFC was measured using the short form of the NFC scale (Cacioppo et al., 1996). The short form consists of 18 items that assess an individuals' preference for cognitive activities (Cacioppo et al.). Each item was rated on a 5-point Likert type scale ranging from 1 (extremely uncharacteristic) to 5 (extremely characteristic). Sample items are "I would prefer complex to simple problems" and "I like tasks that require little thought once I have learned them.” Nine of the items were reversed scored. The measure was scored by taking the sum of all 18 items and averaged, with higher scores indicating higher NFC (Cacioppo \& Petty, 1982). A Cronbach’s alpha coefficient for the 18 items measuring NFC is .98 , suggesting that the scale has a high internal consistency.

Previous job exposure. Previous job exposure was measured using one item. This item asked whether participants were currently a licensed registered nurse or a nursing intern (i.e., no previous job exposure).

Manipulation check. Based on the study conducted by Saks (1989), the success of the job preview manipulation were tested using five questions anchored by a 5 point Likert scale ranging from 1 (strongly disagree) to 5 (strongly agree). These questions were designed to examine the extent to which participants viewed the job preview to be "realistic.” Sample items include "I was given negative information about the job.” and "I was told only good things about the job.” Responses to these questions were averaged 
for each participant to create a single score. A Cronbach's alpha coefficient for the five items is .83, suggesting that the scale has a high internal consistency.

Demographic information. Participants were asked to complete several

demographic questions including their age, gender, ethnicity, years of job experience, and number of hours worked per week. 


\section{Results}

\section{Manipulation Check}

The effectiveness of the job preview manipulation was assessed with a one-way analysis of variance (ANOVA). Results showed that the job preview manipulation was effective, $F(1,161)=79.70, p<.001$. As expected, those in the RJP condition perceived the job as more realistic and negative $(M=3.46, S D=.59)$ than those in the TJP condition $(M=2.60, S D=.64)$.

\section{Descriptive Statistics}

Participants rated the job as moderately attractive $(M=3.18, S D=1.34)$. Participants also rated the organization as moderately honest $(M=3.14, S D=1.32)$. In terms of job acceptance, only $45 \%$ of the participants reported that they would accept the position if offered. Participants also had a moderate level of NFC $(M=3.29, S D=1.19)$.

Table 2 presents zero-order correlations among type of job preview and the measured variables. Correlation coefficients between type of job preview and the measured variables show that type of job preview was not strongly related to any of the measured variables. NFC was related to job attractiveness $(r=-.33, p=.01)$, job acceptance decision $(r=.37, p=.01)$, and perception of organizational honesty $(r=-.37$, $\mathrm{p}<.01$ ) such that those with higher NFC were likely to rate the job as less attractive, accept the job less often, and perceive the organization as less honest. Both job attractiveness $(\mathrm{r}=-.33, \mathrm{p}<.01)$ and perceptions of organizational honesty $(\mathrm{r}=-.59, \mathrm{p}<$ .01) were related to job acceptance decision such that those who rated the job more attractive and perceived the organization as more honest accepted the job. 
Table 2. Correlations Among Measured Variables

\begin{tabular}{|c|c|c|c|c|c|c|}
\hline Variables & 1 & 2 & 3 & 4 & 5 & 6 \\
\hline Type of Preview & - & & & & & \\
\hline Previous Job Exposure & .02 & - & & & & \\
\hline Need for Cognition & -.12 & $-.16^{*}$ & - & & & \\
\hline Job Attractiveness & .07 & -.10 & $-.33 * *$ & - & & \\
\hline Job Acceptance Decision & -.07 & .13 & $.37 * *$ & $-.33 * *$ & - & \\
\hline $\begin{array}{l}\text { Perception of } \\
\text { Organizational Honesty }\end{array}$ & -.07 & -.11 & $-.37 * *$ & $.95^{* *}$ & $-.59 * *$ & - \\
\hline
\end{tabular}

Note. Type of job preview. $1=$ Realistic job preview, $2=$ Traditional job preview.

Previous job exposure. $=1=$ Registered Nurse, $2=$ Nursing Intern

Job acceptance decision . 1 = Yes, 2 = No 


\section{Tests of Hypotheses}

Hypothesis 1a stated that previous job exposure would moderate the effects of type of job preview on job attractiveness such that those with no previous exposure to the job would rate the preview that contains only positive information (TJP) as more attractive than the preview that contains both positive and negative information (RJP). In contrast, those with previous job exposure were hypothesized to rate the RJP as more attractive than the TJP. This hypothesis was tested using a 2 (type of job preview: RJP vs. TJP) x 2 (previous job exposure: with vs. without) between-subjects analysis of variance (ANOVA) with Type I error rate of .05.

Results of the ANOVA showed a non-significant main effect for type of job preview, $F(1,159)=2.44, p=.12$, a non-significant main effect for job exposure, $F$ $(1,159)=1.88, p=.17$, but a significant interaction effect between the two, $F(1,159)=$ 4.07, $p<.05$. Table 3 shows an ANOVA summary table. As expected, the interaction between type of job preview and job exposure was significant. In order to understand the nature of the interaction effect, a simple effects analysis was conducted. Results of the simple effects analysis showed that there was no significant difference in job attractiveness ratings between the RJP $(M=3.23, \mathrm{SD}=1.29)$ and $\mathrm{TJP}(\mathrm{M}=3.13, \mathrm{SD}=$ 1.39) conditions among those with previous job exposure (registered nurses), $F(1,159)=$ $.18, p=.67$. However, those with no previous job exposure (nursing interns) rated the job as significantly more attractive when they were exposed to the TJP $(M=3.27, S D=$ 1.28) than when presented with the RJP $(M=2.48, \mathrm{~S} D=1.31), F(1,159)=11.91, p<$ 
.01. Figure 1 presents means for job attractiveness as a function of type of job preview and previous job exposure. These results show partial support for Hypothesis 1a.

Table 3. ANOVA Summary Table

\begin{tabular}{lcccc}
\hline Source & $S S$ & $d f$ & $M S$ & $F$ \\
\hline Type of job preview (JP) & 4.33 & 1 & 4.33 & 2.44 \\
Job exposure (JE) & 3.33 & 1 & 3.33 & 1.88 \\
JP x JE & 7.22 & 1 & 7.22 & $4.07^{*}$ \\
Error & 282.2 & 159 & 1.77 & \\
\hline
\end{tabular}

Note. ${ }^{*} \mathrm{p}<.05$

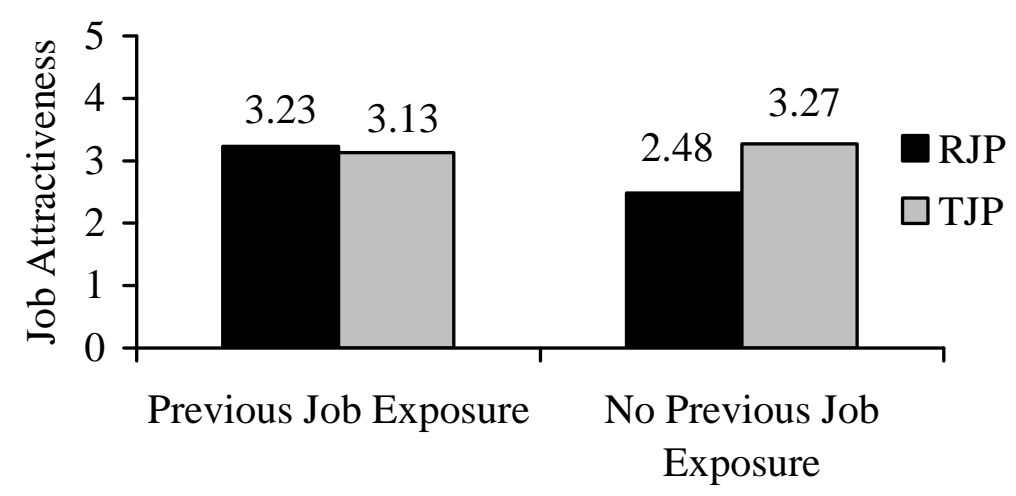

Figure 1. Job attractiveness as a function of type of job preview and previous job exposure 
Hypothesis $1 \mathrm{~b}$ stated that previous job exposure would moderate the effects of type of job preview on a job acceptance decision such that those with no previous job exposure would accept the job more often when presented with the TJP than when presented with the RJP. In contrast, those with previous job exposure were hypothesized to accept the job presented with the RJP more often than the job presented with the TJP. This hypothesis was tested using a $x^{2}$ test with Type I error rate of .05 . The frequency distribution of job acceptance as a function of previous job exposure and type of job preview is displayed in Table 4. Results of the $X^{2}$ test showed no significant difference in the job acceptance rate as a function of type of job preview among those with previous job exposure, $\chi^{2}(1, \mathrm{~N}=163)=1.23, p=.54$. Those with previous job exposure appeared to accept the job more often than not, regardless of type of job preview. However, a significant difference in the job acceptance rate as a function of type of job preview was found among those with no previous job exposure, $\chi^{2}(1, \mathrm{~N}=163)=9.70, p<.01$. That is, interns accepted the job more often when they were presented with the TJP, but when they were presented with the RJP, the results were split between those that accepted and those that did not. Thus, Hypothesis $1 \mathrm{~b}$ was partially supported. 
Table 4. Frequency Distribution of Job Acceptance as a Function of Job Exposure and Type of Job Preview

\begin{tabular}{lccccc}
\hline & \multicolumn{3}{c}{ Previous Job Exposure } & No Previous Job Exposure \\
\hline & & RJP & TJP & RJP & TJP \\
\hline Accept: & Yes & 35 & 31 & 17 & 19 \\
\hline No & 20 & 21 & 18 & 8 \\
\hline
\end{tabular}

Hypothesis 1c stated that previous job exposure would moderate the effects of type of job preview on the perceived honesty of an organization such that those with no previous job exposure would perceive the organization as more honest when presented with the TJP than when presented with the RJP. In contrast, those with previous job exposure were hypothesized to perceive the organization to be more honest when presented with the RJP than when presented with the TJP. This hypothesis was tested using a 2 (type of job preview: RJP vs. TJP) x 2 (previous job exposure: with vs. without) ANOVA with Type I error rate of .05.

Results of the ANOVA showed a non-significant main effect for type of job preview, $F(1,159)=2.17, p=.14$, a non-significant main effect for previous job exposure, $F(1,159)=2.23, p=.14$, and a non-significant interaction effect between the two, $F(1,159)=3.58, p=.06$. Those with no previous job exposure did not perceive the organization any more honest when presented with the TJP $(\mathrm{M}=3.54, \mathrm{SD}=1.05)$ than when presented with the RJP $(\mathrm{M}=2.35, \mathrm{SD}=1.21)$. Although not statistically significant, the direction of the mean difference in the TJP was consistent with the 
hypothesis. Those with previous job exposure did not perceive the organization any more honest when presented with the RJP $(\mathrm{M}=3.24, \mathrm{SD}=1.29)$ than when presented with the TJP $(M=3.17, S D=1.39)$. Thus, Hypothesis $1 \mathrm{c}$ was not supported. Table 5 shows an ANOVA summary table. Figure 2 displays the mean perception of organizational honesty as a function of type of job preview and previous job exposure.

Table 5. ANOVA Summary Table

\begin{tabular}{lcccc}
\hline Source & SS & df & MS & F \\
\hline Type of job preview (JP) & 3.92 & 1 & 3.92 & 2.2 \\
Job exposure (JE) & 4.04 & 1 & 4.04 & 2.2 \\
JP x JE & 6.47 & 1 & 6.47 & 3.6 \\
Error & 286.9 & 159 & 1.80 & \\
\hline
\end{tabular}

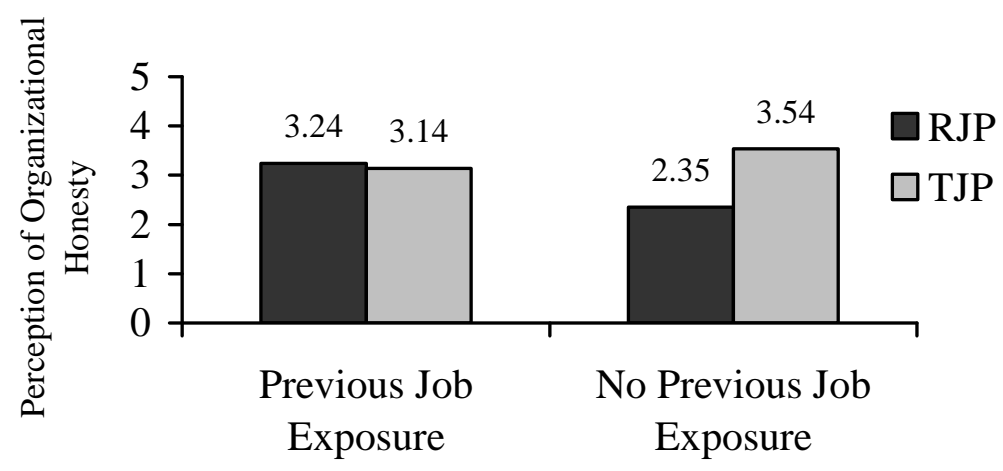

Figure 2. Mean perception of organizational honesty as a function of type of job preview and previous job exposure 
Hypothesis 2a stated that NFC would moderate the effects of type of job preview on job attractiveness such that those high in NFC would rate the RJP as more attractive than the TJP. In contrast, those low in NFC were hypothesized to rate the TJP as more attractive than the RJP. This hypothesis was tested using a hierarchical multiple regression analysis (MRC) with Type I error rate of .05.

Type of job preview was entered in step 1. Results showed that it accounted for $1 \%$ of variance in job attractiveness, $R^{2}=.10, F(1,153)=1.38, p=.24$. NFC was entered in step 2. Type of job preview and NFC together explained $14 \%$ of variance in job attractiveness, $R^{2}=.14, F(1,152)=11.90, p<.01$. NFC accounted for a significant change in variance in job attractiveness, $\Delta R^{2}=.13, F(1,152)=22.22, p<.01$. Results show that those with higher NFC rated the job as less attractive. Finally, the interaction between type of job preview and NFC was entered in step 3. Results showed that two main effects (type of job preview and NFC), and the interaction term together explained $39 \%$ of variance in job attractiveness, $R^{2}=.39, F(1,151)=32.07, p<.01$. The interaction term explained additional variance in job attractiveness, $\Delta R^{2}=.25, F(1,151)$ $=62.76, p<.01$. 
Table 6. Hierarchical MRC Table for the Variable Job Attractiveness

\begin{tabular}{lccc}
\hline & \multicolumn{3}{c}{ Job Attractiveness } \\
& $\beta$ & $\mathrm{R}^{2}$ & $\Delta \mathrm{R}^{2}$ \\
\hline & & & \\
Step 1: & .10 & .01 & .01 \\
Type of job preview (JP) & & & \\
Step 2: & -.36 & $.14^{* *}$ & $.13^{* *}$ \\
NFC & & & \\
Step 3: & & & \\
JP x NFC & -2.03 & $.39^{* *}$ & $.25^{* *}$ \\
\hline
\end{tabular}

Note. ${ }^{*} \mathrm{p}<.05 . * * \mathrm{p}<.01$.

Because the interaction between type of job preview and NFC on job attractiveness was significant, in order to understand the nature of the interaction between them, NFC was split at the median to create low and high NFC conditions. Simple effects analyses of type of job at each level of NFC were conducted. Results of the simple effects analyses revealed that those high in NFC rated the job more attractive when they were presented with the RJP $(M=3.06, S D=1.27)$ than when they were presented with the TJP $(M=1.92, S D=.66), F(1,159)=18.13, p<.01$. In contrast, those low in NFC rated the job more attractive when they were presented with the TJP ( $M$ $=4.26, S D=.52)$ than when they were presented with the RJP $(M=2.80, S D=1.40), F$ $(1,159)=48.87, p<.01$. These results support Hypothesis 2 a. 


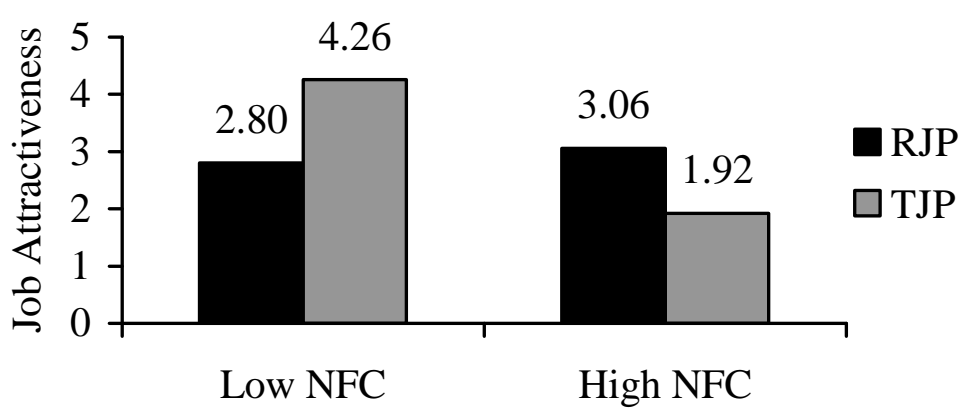

Figure 3. Job attractiveness as a function of type of job preview and NFC

Hypothesis 2b stated that NFC would moderate the effects of type of job preview on a job acceptance decision such that those high in NFC would accept the job more often when presented with the RJP than when presented with the TJP. In contrast, those low in NFC were hypothesized to accept the job presented with the TJP more often than the job presented with the RJP. This hypothesis was tested using a $\chi^{2}$ test with Type I error rate of .05. Again, NFC was split at the median to create low and high NFC conditions.

The frequency distribution of the job acceptance decision as a function of NFC and type of job preview is displayed in Table 7. Results of the $\chi^{2}$ test showed a significant difference in job acceptance decisions as a function of type of job preview among those high in NFC, $\chi^{2}(1, \mathrm{~N}=161)=24.16, p<.001$. While those high in NFC accepted the job more often than not when presented in the RJP, not a single participant accepted the job when presented in the TJP. 
Results also showed a significant difference in job acceptance decision as a function of type of job preview among those low in NFC, $\chi^{2}(1, \mathrm{~N}=161)=39.34, p=$ .001. Those low in NFC accepted the job presented in the TJP more often than the job presented in the RJP. Thus, Hypothesis 2b was supported.

Table 7. Frequency Distribution of Job Acceptance as a Function of NFC and Type of Job Preview

\begin{tabular}{lccccc} 
& & \multicolumn{2}{c}{ Low NFC } & \multicolumn{2}{c}{ High NFC } \\
\cline { 3 - 6 } & & RJP & TJP & RJP & TJP \\
\hline Accept: & Yes & 11 & 41 & 29 & 0 \\
\hline & No & 24 & 4 & 18 & 36 \\
\hline
\end{tabular}

Hypothesis 2c stated that NFC would moderate the effects of type of job preview on perceived honesty of an organization such that those high in NFC would perceive the organization as more honest when presented with the RJP than when presented with the TJP. In contrast, those low in NFC were hypothesized to perceive the organization as more honest when presented with the TJP than when presented with the RJP. This hypothesis was tested using a hierarchical multiple regression analysis (MRC) with Type I error rate of .05.

Type of job preview was entered in step 1. Results showed that it accounted for $1 \%$ of variance in perception of organizational honesty, $R^{2}=.01, F(1,153)=1.06, p=$ 
.31. Type of job preview did not have an effect on the perceived honesty of the organization. NFC was entered in step 2. Results showed that type of job preview and NFC together accounted for $17 \%$ of variance in perception of organizational honesty, $R^{2}$ $=.17, F(1,152)=15.16, p<.01$. NFC accounted for a significant change in variance in perception of organizational honesty, $\Delta R^{2}=.16, F(1,152)=29.07, p<.01$. Results showed that those with higher NFC perceived the organization as less honest. Finally, the interaction between type of job preview and NFC was entered in step 3. Results showed that type of job preview, NFC, and the interaction term together explained $41 \%$ of variance in perception of organizational honesty, $R^{2}=.41, F(1,151)=34.27, p<.01$. The interaction term explained additional variance in perception of organizational honesty, $\Delta R^{2}=.24, F(1,151)=60.59, p<.01$.

Because the interaction between type of job preview and NFC on perception of organizational honesty was significant, in order to understand the nature of the interaction between them, NFC was split at the median to create low and high NFC conditions. Simple effects analyses of type of job at each level of NFC were conducted. Results of the simple effects analysis showed that those high in NFC rated the organization as more honest when they were presented with the RJP $(M=3.04, S D=1.22)$ than when they were presented with the TJP $(M=1.92, S D=.83), F(1,159)=16.11, p<.001$. In contrast, those low in NFC rated the organization as more honest when they were presented with the TJP $(M=4.28, S D=.60)$ than when they were presented with the RJP 
$(M=2.93, S D=1.37), F(1,159)=41.81, p<.001$. These results support Hypothesis 2c.

Table 8. Hierarchical MRC Table for the Variable Perception of Organizational Honesty

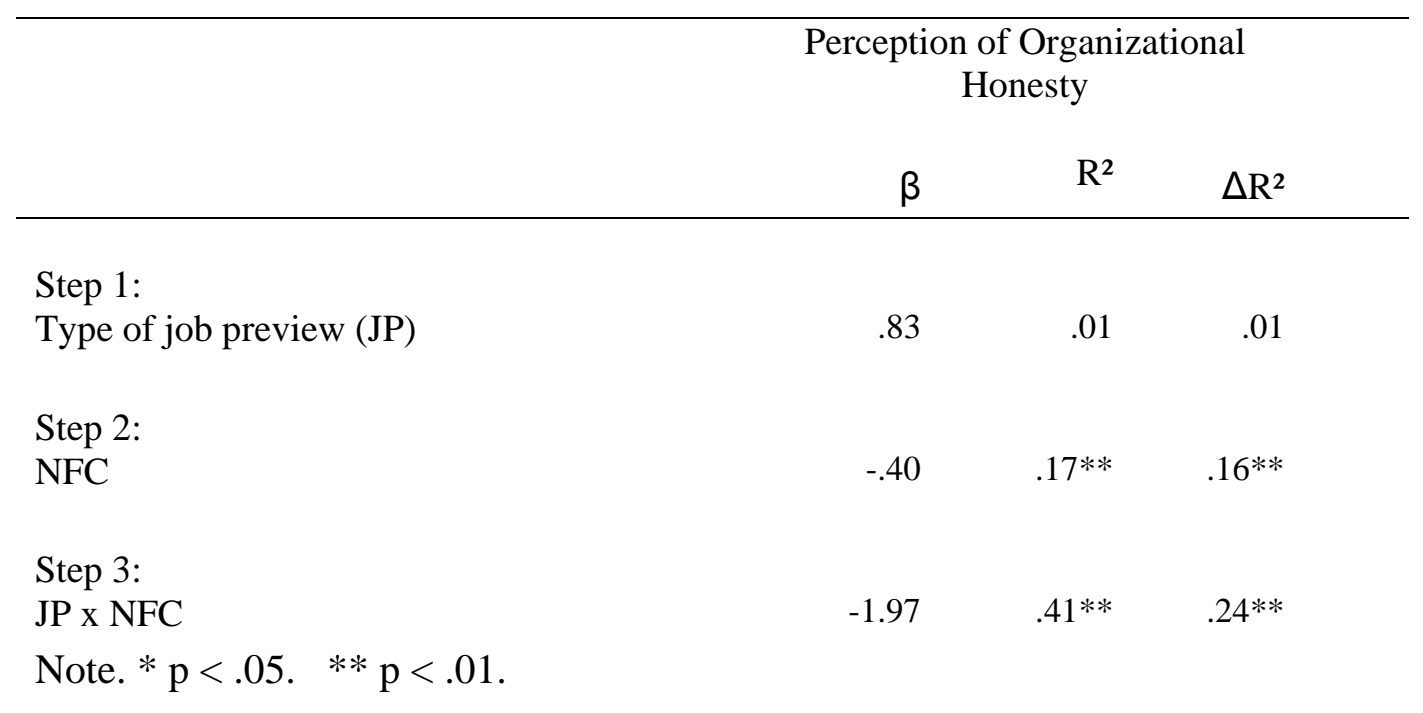

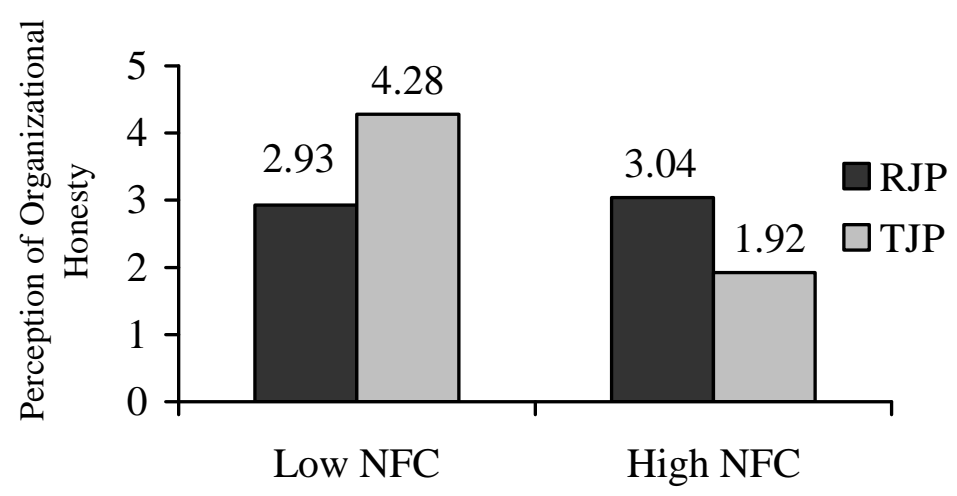

Figure 4. Perception of organizational honesty as a function of type of job preview and NFC 


\section{DISCUSSION}

In order to recruit and retain top quality employees, organizations need to put a substantial amount of effort into perfecting their recruitment procedures. One possible way for organizations to recruit and retain the best candidates is by using RJPs, because they are likely to have a great impact on a potential applicant's formation of opinions about the job and the organization (Phillips, 1998). To ensure that organizations are maximizing their recruiting efforts, it is necessary to understand the influence that RJPs have on recruitment efforts. Although past research has shown the beneficial impact of RJPs such as reduced turnover, increased organizational commitment, and improved job performance, mixed results have also been reported (Phillips, 1998; Suszko \& Breaugh, 1986). Because the success of the RJP might be contingent on how the individual interprets the information presented in job previews, it has been argued that researchers need to pay more attention to the characteristics of potential applicants (Adeyemi-Bello \& Mulvaney, 1995). Therefore, the present study sought to expand past literature by examining two individual characteristics - previous job exposure and NFC - and by hypothesizing that they serve as a moderator on the effect of type of job preview on job attractiveness, the rate of job acceptance, and perception of organizational honesty.

Hypotheses 1a through 1c stated that previous job exposure would moderate the effects of type of job preview on (a) job attractiveness (H1a), (b) a job acceptance decision $(H 1 b)$, and (c) perception of organizational honesty $(H 1 c)$ such that those with no previous job exposure would rate the job as more attractive, accept the job more often, and perceive the organization as more honest when presented with the TJP than when 
presented with the RJP. The opposite patterns were expected for those with previous job exposure. Most of these hypotheses were supported. That is, those with no previous job exposure rated the job as more attractive and accepted the job more often when presented with the TJP than when presented with the RJP. Although it was not statistically significant, they tended to rate the organization as more honest when presented with the TJP than when presented with the RJP. These findings are not congruent with Meglino et al. (1993) who found that participants with no previous job exposure accepted the RJP position more often than the TJP position. One possible reason for such inconsistency is that Meglino et al.'s RJP contained negative information regarding the noxious events of the position, but also contained two times the amount of positive information regarding the job. The positive information may have had a greater impact compared to the negative information given, thus those with no previous exposure might have paid more attention to the positive information and been influenced by such positive information more than by the negative information.

The results of the present study also showed that those with previous job exposure did not rate the job any more attractive, accept the job any more often, and perceive the organization as any more honest when presented with the RJP than when presented with the TJP. These findings are not consistent with Lichtenstein et al.'s (1978) findings. They found that those individuals with previous job exposure placed more emphasis on the negative information in the RJP compared to those with no exposure, which resulted in lower levels of job attractiveness and lower acceptance rates for the RJP condition. One possible reason for our findings is that those who already had previous exposure to 
the job do not need an RJP because they already understand both positive and negative aspects of the job. Perhaps they do not need to differentiate between the RJP and the TJP because they understand the reality of the position.

The results of the current study indicate that individuals who have job exposure to the position of registered nurse do not necessarily prefer an RJP over a TJP, probably because they already have experience for the position. However, those individuals who have little to no previous exposure to the position of registered nurse do prefer a TJP, probably because they do not understand the negative aspects of the position yet, thus they are likely to rate them more negatively when they are exposed to an RJP.

Hypotheses 2a through 2c stated that NFC would moderate the effects of type of job preview on (a) job attractiveness (H2a), (b) a job acceptance decision (H2b), and (c) perception of organizational honesty $(\mathrm{H} 2 \mathrm{c}$ ) such that those high in NFC would rate the job as more attractive, accept the job more often, and perceive the organization as more honest when presented with the RJP than when presented with the TJP. The opposite patterns were expected for those with low levels of NFC. All of these hypotheses were supported. That is, those who were high in NFC rated the job as more attractive, accepted the job more often, and rated the organization as more honest when presented with the RJP than when presented with the TJP. Interestingly, results showed that not a single registered nurse accepted the job when presented with TJP. In contrast, those individuals who were low in NFC were found to rate the job as more attractive, accept the job more, and rate the organization as more honest when presented with the TJP. These findings are consistent with Buda and Charnov (2003) who found that individuals 
who are low in NFC rated the RJP as significantly less attractive than the TJP and also showed that those high in NFC rated the negatively framed message (the RJP) as significantly more attractive than the same job with a positively framed message (the TJP).

Results of the current study indicate that individuals do in fact process information differently depending on their level of NFC and previous exposure to a job. That is, those low in NFC are not likely to engage in careful processing of information when it contains both positive and negative information (RJP) and consequently have lower expectations about the job which is likely to result in lower job attractiveness, fewer job acceptances, and decreased perception of an organization's honesty. The same is true with those with no previous job exposure. When presented with a job preview that contains negative aspects of a job, applicants with no previous exposure might pay more attention to the negative information which may result in lower expectations and thus they do not see the job as attractive and are less likely to accept the job offer. This study provides additional support for the past research that job previews can influence an individual's assessment of the attractiveness of the job, the rate of job acceptance, and the perception of organizational honesty.

\section{Implication of Findings}

Theoretical implications. The current study supports the results of Premack and Wanous' (1985) self-selection hypothesis, which demonstrates that job seekers could be influenced by the presence of RJPs. Those with less exposure and lower levels of NFC may not feel that they are a good match for an organization or a job, thus, they might 
withdraw from a recruitment process, by rating the organization in an RJP as less attractive, accepting the job less, and perceiving the organization as less honest than when given a TJP. Information given in an RJP may actually increase individuals' accuracy in assessing whether they have the skills and abilities necessary to perform the tasks associated with the job successfully (Gardner, Foo, \& Hesketh, 1995). This would explain the findings of this study, in that applicants who are the best fit to perform the tasks and realistically understand the demands of the job -- those who are high in NFC and have previous exposure -- will prefer the RJP to the TJP.

Results of the study also imply that reactions to job previews are not universal. They depend on type of job previews and individual characteristics. Certain types of individuals react more positively to one type of job preview over the other type. These findings indicate that research on job previews need to pay more attention to individual characteristics and understand how they react to different types of job previews in order to select the right candidates while turning away those who will not be a good fit for the position.

Practical implications. Considering that most of the hypotheses were supported, there are several practical implications for organizations and job seekers alike. The results of the present study imply that organizations need to consider a different type of job preview depending on the characteristics of job applicants. For example, given the findings that the responses of those with previous job exposure were not influenced by type of job preview given, it may not matter which job preview should be given to them. Furthermore, given that those high in NFC rated the position of registered nurse as more 
attractive, perceived the organization as more honest, and accepted the job more when presented with the RJP, the organization should use RJPs in recruitment efforts. This might provide subsequent benefits for organizations because those individuals who score high in NFC tend to be more task-oriented, intrinsically motivated, and can be unbiased by the inclusion of negative information (Tidwell, Sadowski, \& Pate, 2000).

However, given the findings that those with no previous job exposure and those with low NFC rated the job more attractive, accepted the job more often, and perceived the organization as more honest when presented with the TJP than with the RJP, organizations might be better off to use a TJP when they recruit such individuals. Such individuals might be turned off by the negative aspects of a job presented in an RJP. However, RJPs can be beneficial even when organizations try to recruit or hire those individuals. Susko and Breaugh (1986) used an RJP before the final interview and during the standard training and found that those who received the RJP perceived the organization as more straightforward and truthful, reported higher levels of satisfaction with the position, were better able at coping with the demands of the job, and were less likely to voluntarily leave the company compared to those who did not receive the RJP. Therefore, if the organization does not want to turn away those without previous experience or individuals lower in NFC, then they can still benefit from the positive outcomes associated with the use of RJPs by changing the timing of when applicants are presented with the RJP.

RJPs can also help applicants because they are given more complete information about the job and the organization, which allows them to make more informed decisions 
about the job. This would result in decreased turnover, increased job satisfaction, increased organizational commitment, and increased performance (Phillips, 1998; Premack \& Wanous, 1985). By utilizing RJPs in recruitment efforts, the organization has the potential to reduce the number of lower quality applicants, reduce unrealistic expectations about the job for potential applicants, and recruit individuals who will have a strong person-organization fit. This is likely to yield positive results for both the organization and the employee in the long term.

\section{Strengths, Limitations, and Future Research}

One strength of this study is that it showed that the effects of job previews were not universal. It showed the type of job preview had different effects depending on the characteristics of participants. Given that past research has seldom paid attention to audience characteristics, results of the study add to the literature on RJPs. A second strength of this study is that unlike the majority of the past studies, it did not rely on students as participants, but relied on individuals who were actually working or interning in the field of nursing. A common limitation addressed in much research is that it only involved the use of students. Since most participants had experience working in the field of nursing, the job previews used in this study are more realistic and they can actually relate to them because nursing is their chosen profession. Past research in the area of RJPs has had problems because it used students and since they are not familiar with the position in an RJP, they may actually overly focus on the negative information, thus rating the job as less attractive (Smith \& Petty, 1996). This study overcame such 
weakness by utilizing individuals who are currently in the field of nursing, which might be one of the reasons for the many significant findings in the present study.

Despite the strengths of the study, this study is not without limitations. One of the limitations of this research is that the two samples used were slightly one-sided. A large number of the participants were registered nurses. Only 55 out of the 163 participants were interns. Even though there were a smaller number of interns compared to registered nurses, this study was still able to find significant results, which could mean that if a larger sample of interns were used, one would have more confidence in the results.

A second limitation of this research is that only pre-hire outcomes were measured. Therefore, it is not known whether the effects of type of preview on post-hire outcomes such as job satisfaction, turnover intentions, and organizational commitment would change as a function of previous job exposure and NFC levels. Therefore, it is not known how much it would affect an organization's bottom line if they were able to attract and retain individuals who have previous experience in the job and who are high in NFC. In essence, just finding that RJPs could aid in selecting those with more job experience and higher levels of NFC is a step in the right direction, but without knowing how it affects employees' post-hire performance and attitudes, it is not completely clear what effects RJPs have on the organizations bottom line.

Therefore, future research should focus on both pre-hire outcomes and post-hire outcomes in order to assess the effectiveness of using RJPs in an organizational setting, 
as well as how RJPs affect organizational performance. The next logical step would be for researchers to follow people who do select the job as they journey through the organization and examine what the post-hire implications of using RJPs in recruitment are.

Future research may also benefit by examining how NFC scores relate to the specific job used in the RJP. Because NFC indicates an individual's degree of preference for effortful thoughts, the complexity of a job description might make a difference among those with different levels of NFC. Because the position of registered nurse is a relatively complex job, those low in NFC might have reacted positively to the TJP. However, if the job is less complex, even if the description of the job contains negative aspects of the job, those with low on NFC might not react negatively to an RJP. Future research should look at jobs that differ in complexity, and how those with different levels of NFC would react to an RJP and a TJP. This would allow the present results to generalize across different types of jobs in order to see what jobs are best suited for the use of RJPs. This would allow for human resource professionals to tailor the right recruitment efforts to those who will best benefit from them. This would ensure that organizations are not only recruiting the right people for the right job, but it would ensure that they are hiring those people to result in positive gains for the organization.

\section{Conclusion}

Increasing the efficiency while capitalizing on recruitment efforts in organizations is becoming more and more important as the unemployment rates continue to rise and more and more people are seeking jobs. Since a job preview is truly the first place where 
potential applicants form opinions about the job and the organization, it is important to make sure that these first impressions are good ones. Research has shown the beneficial outcomes of utilizing RJPs in recruitment, therefore, organizations can in fact tailor their recruitment messages in order to attract and hopefully retain the right people, in the right job with the right organization. However, given that reactions to RJPs vary as a function of individual characteristics, understanding the role individual differences like previous job exposure and NFC play in the recruitment of employees is another step towards maximizing the recruitment process, which is likely to help both the employee and the organization in the long term. 


\section{References}

Adeymi-Bello, T., \& Mulvaney, W. (1995). The development and administration of realistic job previews. Equal Opportunities International,14(5), 1-7.

Avner, B. K., Guastello, S. J., \& Aderman, M. (1982). The effect of a realistic job preview on expectancy and voluntary versus involuntary turnover. The Journal of Psychology, 111(2), 101-107.

Breaugh, J. A. (1983). Realistic job previews: A critical appraisal and future research directions. The Academy of Management Review, 8, 612-619.

Breaugh, J. A., Macan, T. H., \& Grambow, D. M. (2008). Employee recruitment: Current knowledge and directions for future research. In G.P. Hodgkinson, and J. K. Ford (Eds.), International Review of Industrial and Organizational Psychology (pp. 45-82). New York: John Wiley.

Breaugh, J. A., \& Starke, M. (2000). Research on employee recruitment: So many studies, so many remaining questions. Journal of Management, 26, 405-434.

Bretz, R. D., \& Judge, T. A. (1998). Realistic job previews: A test of the adverse selfselection hypothesis. Journal of Applied Psychology, 83, 330-337.

Buda, R., \& Charnov, B. H. (2003). Message processing in realistic recruitment practices. Journal of Managerial Issues, 15, 302-316.

Cacioppo, J. T., \& Berntson, G. G. (1994). Relationship between attitudes and evaluative space: A critical review, with emphasis on the separability of positive and negative substrates. Psychological Bulletin, 115, 401-423.

Cacioppo, J. T., Petty, R. E., Feinstein, J. A., \& Jarvis, B. G. (1996). Dispositional differences in cognitive motivation: The life and times of individuals varying in need for cognition. Psychological Bulletin, 119, 197-253.

Cacioppo, J. T., Petty, R. E., \& Kao, C. F. (1984). The efficient assessment of need for cognition. Journal of Personality Assessment, 48, 306-307.

Colarelli, S. M. (1984). Methods of communication and mediating processes in realistic job previews. Journal of Applied Psychology, 69, 633-642.

Daft, R. L., \& Lengel, R. H. (1986). Organizational information requirements, media richness and structural design. Management Science, 32, 554-571. 
Dean, R. A., \& Wanous, J. P. (1984). Effects of realistic job previews on hiring bank tellers. Journal of Applied Psychology, 69, 61-68.

Dilla, B. L. (1987). Descriptive versus prescriptive information in a realistic job preview. Journal of Vocational Behavior, 30, 33-48.

Dugoni, B. L., \& Ilgen, D. R. (1981). Realistic job previews and the adjustment of new employees. The Academy of Management Journal, 24, 579-591.

Eagly, A., \& Himmelfarb, S. (1978). Attitudes and opinions. Annual Review of Psychology, 29, 517-554.

Gardner, D., Foo, M. H., \& Hesketh, B. (1995). Realistic job previews: information processing and the accuracy of self-assessment. Australian Psychologist, 30, 6470.

Green, J. H., Brooke, V. (2001). Recruiting and retaining the best from America's largest untapped talent pool. Journal of Vocational Rehabilitation, 16(2), 83-88.

Haugtvedt, C., Petty, R., \& Cacioppo, J. (1992). Need for cognition and advertising: Understanding the role of personality variables in consumer behavior. Journal of Consumer Psychology, 1(3), 239-260.

Hom, P. W., Griffeth, R. W., Palich, L. E., \& Bracker, J. S. (1999). Revisiting met expectations as a reason why realistic job previews work. Personnel Psychology, 52, 97-112.

Ilgen, D. R., Seely, W. (1974). Realistic expectations as an aid in reducing. voluntary resignations. Journal of Applied Psychology, Vol 59(4), 452-455.

Irving, P. G., \& Coleman, D. F. (1997). The influence of source credibility attributions on expectancy theory predictions of organizational choice. Canadian Journal of Behavioral Science, 29, 122-131.

Irving, P., \& Montes, S. (2009). Met expectations: The effects of expected and delivered inducements on employee satisfaction. Journal of Occupational and Organizational Psychology, 82(2), 431-451.

Janis, I. (1958). Psychological stress: Psychoanalytic and behavioral studies of surgical patients (pp. 3-13). Hoboken, NJ US: John Wiley \& Sons Inc.

Lee, T., Ashford, S., Walsh, J., \& Mowday, R. (1992). Commitment propensity, organizational commitment, and voluntary turnover: A longitudinal study of organizational entry processes. Journal of Management, 18(1), 15-32. 
Lichtenstein, S., Slovic, P., Fischhoff, B., Layman, M., \& Combs, B. (1978). Judged frequency of lethal events. Journal of Experimental Psychology: Human Learning and Memory, 4(6), 551-578.

Meglino, B. M., \& DeNisi, A. S. (1987). Realistic job previews: Some thoughts on their more effective use in managing the flow of human resources. Human Resource Planning, 10(3), 157-167.

Meglino, B. M., DeNisi, A. S., Youngblood, S. A., \& Williams, K. J. (1988). Effects of realistic job previews: A comparison using an enhancement and a reduction preview. Journal of Applied Psychology, 73, 259-266.

Meglino, B. M., DeNisi, A. S., \& Ravlin, E. C. (1993). Effects of previous job exposure and subsequent job status on the functioning of a realistic job preview. Personnel Psychology, 46, 803-822.

Meglino, B. M., Ravlin, E. C., \& DeNisi, A. S. (1997). When does it hurt to tell the truth? The effect of realistic job reviews on employee recruiting. Public Personnel Management, 26, 413-423.

Meglino, B. M., Ravlin, E. C., \& DeNisi, A. S. (2000) A meta-analytic examination of realistic job preview effectiveness: A test of three counterintuitive propositions. Human Resource Management Review, 10, 407-434.

Phillips, J. M. (1998). Effects of realistic job previews on multiple organizational outcomes: A meta-analysis. The Academy of Management Journal, 41, 673-690.

Pitt, L. F., \& Ramaseshan, B. (1995). Realistic job information and sales force turnover: An investigative study. Journal of Managerial Psychology, 10, 29-36.

Popovich, P., \& Wanous, J. P. (1981). The realistic job preview as a persuasive communication. Academy of Management Review, 7, 570-578.

Porter, L., \& Steers, R. (1973). Organizational, work, and personal factors in employee turnover and absenteeism. Psychological Bulletin, 80(2), 151-176.

Premack, S. L., \& Wanous, J. P. (1985). A meta-analysis of realistic job preview experiments. Journal of Applied Psychology, 70, 706-719.

Reilly, R. R., Brown, B., Blood, M. R., \& Malatesta, C. Z. (1981). The effects of realistic previews: A study and discussion of the literature. Personnel Psychology, 34,823-834. 
Rynes, S. (1991). Recruitment, job choice, and post-hire consequences: A call for new research directions. Handbook of industrial and organizational psychology, Vol.2 (2nd ed.) (pp. 399-444). Palo Alto, CA US: Consulting Psychologists Press. Retrieved from PsycINFO database.

Saks, A. M. (1989). An examination of the combined effects of realistic job previews, job attractiveness and recruiter affect on job acceptance decisions. Applied Psychology: An International Review, 38, 145-163.

Saks, A. M., \& Cronshaw, S. F. (1990). A process investigation of realistic job previews: Mediating variables and channels of communication. Journal of Organizational Behavior, 11, 221-236.

Saks, A. M., Wiesner, W. H., \& Summers, R. J. (1994). Effects of job previews on self-selection and job choice. Journal of Vocational Behavior, 44, 297-316.

Saks, A. M., Wiesner, W. H., \& Summers, R. J. (1996). Effects of job previews and compensation policy on applicant attraction and job choice. Journal of Vocational Behavior, 49, 68-85.

Smith, S. M, \& Petty, R. E. (1996). Message framing and persuasion: A message processing analysis. Personality and Social Psychology Bulletin, 22, 257- 268.

Suszko, M. K., \& Breaugh, J. A. (1986). The effects of realistic job previews on applicant self-selection and employee turnover, satisfaction, and coping ability. Journal of Management, 12, 513-523.

Tidwell, P. S., Sadowski, C. J., \& Pate, L. M. (2000). Relationships between need for cognition, knowledge, and verbal ability. Journal of Psychology: Interdisciplinary and Applied, 134(6), 634-644.

U.S. Bureau of Labor Statistics (2010). Unemployment rates in the west region, seasonally adjusted (in percent), Retrieved June 17, 2010 from: http://www.bls.gov/xg_shells/ro9xg02.htm\#rate

Wanous, J. P. (1973). Effects of a realistic job preview on job acceptance, job attitudes, and job survival. Journal of Applied Psychology, 58, 327-332.

Wanous, J. P. (1989). Installing a realistic job preview: Ten tough choices. Personnel Psychology, 42, 117-133.

Wanous, J. P., Poland, T., Premack, S., \& Davis, K. (1992). The effects of met expectations on newcomer attitudes and behaviors: A review and meta-analysis. Journal of Applied Psychology, 77(3), 288-297. 
Wiesner, W. H., Saks, A. M., \& Summers, R. J. (1991). Job alternatives and job choice. Journal of Vocational Behavior, 38, 198-207.

Young, I., Rinehart, J., \& Heneman, H. (1993). Effects of job attribute categories, applicant job experience, and recruiter sex on applicant job attractiveness ratings. Journal of Personnel Evaluation in Education, 7(1), 55-66. 